\title{
Biofilm capability of staphylococcus strains isolated from food and the anti- biofilm activity of a chemically synthesized pyrrolomycin
}

\author{
Cusimano M.G ${ }^{1}$. Raimondi M.V. ${ }^{2}{ }^{\S}$ Schillaci $D^{2}$. Nocera $\mathrm{P}^{1}$. Cascioferro $\mathrm{S}^{2}$. Di Marco Lo Presti \\ V. Vitale $\mathbf{M}^{1^{*}}$ \\ ${ }^{1}$ Istituto Zooprofilattico Sperimentale della Sicilia “A. Mirri”, Via Gino Marinuzzi 3, 90129 Palermo \\ (Italy); \\ ${ }^{2}$ Dept. of Biological, Chemical and Pharmaceutical Science and Technology (STEBICEF).University of \\ Palermo, -Palermo Italy
}

$\S$ The two authors contributed equally to the work
*Corresponding Author: Author Maria Vitale , 'Istituto Zooprofilattico Sperimentale della Sicilia "A.
Mirri", Via Gino Marinuzzi 3, 90129 Palermo (Italy); Email: marvitus@ @ahoo.com

Article history; Received: 7 July 2018; Revised: 29 July 2018; Accepted: 2 August 2018

\begin{abstract}
:
This electronic document is a "live" template. The various components of your paper [title, text, tables, figures and references] are already defined on the style sheet, as illustrated by the portions given in this document.
\end{abstract}

Keywords: Biofilm; Staphylococcus spp; ica; bap; Sas C; food isolates; anti-biofilm; pyrrolomycin; antibiofilm

\section{Introduction}

Food transmitted diseases are a big issues for public health worldwide and food-borne outbreaks from several sources are continuously reported caused by different infectious agents, as reviewed in Vitale and Schillaci (2016). Bacterial infection and contamination can be more complex and difficult to treat when pathogenic bacteria are organized in structural community named biofilms. Biofilm bacteria are more resistant to drugs and other treatments and their important role for infectious diseases in animals, has been explored in the last decades (Clutterbuck et al. 2007).

However biofilms are also a big concern for food safety for the contamination of surfaces and equipment in food processing industries (Srey, et al. 2013). Staphylococcus aureus is a relevant pathogen for mastitis in dairy farms and $S$. aureus biofilms are considered important in recurrent mastitis (Melchior et al., 2006).

The intercellular adhesion (ica) locus (Cramton et al., 1999), bap gene (Cucarella et al., 2004) and sas $C$ gene (Schroeder et al., 2009) are involved in the organization of staphylococcal biofilm. The infected animals can contaminate milk, dairy products, meat with a consequent major risk for foodborne transmission to humans. The discovery of new drugs against sessile bacteria is considered a good strategy to control the infection and the diffusion of food transmitted pathogens (Simo es et $a l ., 2010)$.With the aim of discovering new antibacterial drugs active against planktonic bacteria and /or biofilms, we have focused on the pyrrolomycins (Schillaci et al., 2010).

The evaluation of biofilm formation in food isolates of $S$. aureus, in relation to the presence of $i c a$, bap and sas $C$ was performed together with the assays for the antimicrobial activity of a new 
chemically synthesized nitro-derivative pyrrolomycin, the (3,5-dichloro-2-hydroxyphenyl)(4-nitro$1 H$-pyrrol-2-yl)methanone (IV).

\section{Materials and Methods}

Synthesis of compound IV

Synthesis of (3,5-dichloro-2-hydroxyphenyl)(4-nitro-1H-pyrrol-2-yl)methanone (IV). The compound was synthesized and characterised as already described (Raimondi et al., 2006).

Figure 1: Chemical structure of (3,5-dichloro-2-hydroxyphenyl)(4-nitro-1H-pyrrol-2-yl)methanone IV<smiles>O=C(c1cc([N+](=O)[O-])c[nH]1)c1cc(Cl)cc(Cl)c1O</smiles>

IV

\section{Bacterial strains}

Two reference strains: S. aureus ATCC 25923, S. epidermidis RP62A, and a group of 20 food strains of $S$. aureus were analysed. The isolates were subjected to Gram staining and biochemical analysis such as catalase and Voges-Proskauer (VP) test (BioMérieux), oxidase test (Oxoid), glucose and mannitol acidification in red phenol broth (Difco). Further identification was performed using the API Staph system (BioMérieux, Marcy l'Etoile, 20500, France).

\section{MICs determination.}

Minimum inhibitory concentrations (MICs) against planktonic strains were determined as previously described in Schillaci et al. (2010).

\section{Molecular characterization}

DNA was extracted using QIAmp DNA mini kit spin columns according to the manufacturer's instructions (Quiagen SpA, Milan, Italy). Staphylococcus spp. isolates were investigated by PCR for the presence of the intercellular adhesion (ica) locus, biofilm-associated protein (bap) as described in Cucarella et al. (2004) and Sas (Srinivasan et al. 2006).

\section{Biofilm capability evaluation}

All the staphylococcal strains were tested for their ability to form biofilms by safranin staining method ( Schillaci et al., 2010). The same method was also used to evaluate a preventive activity on the three strongest strains by directly adding to the diluted suspension, sub-MIC concentrations of pyrrolomycin IV.

Biofilm susceptibility testing, methylthiazotetrazolium (MTT) method were performed as described in Schillaci et al. (2010)

All biofilm assays were performed in triplicate.

\section{Results}

The results on genes showed that bap was present in 1/20, ica was detected in $16 / 20$ strains and sas $C$ in $8 / 20$ but biofilm capability was not related to the presence of genes. (Table 1 ) 
Table 1: Biofilm capability (Optical Density, O.D.) and genes

\begin{tabular}{|c|c|c|c|c|}
\hline Staphylococcus strains & D.O & $i c a$ & bap & $\operatorname{sas} C$ \\
\hline S.epidermidis RP 62A & 3.010 & + & - & - \\
\hline S.aureus ATCC 25923 & 1.956 & + & - & + \\
\hline S.aureus 708 & 1.896 & + & - & + \\
\hline S.aureus 637 & 1.668 & - & - & - \\
\hline S.aureus 1553 & 1,337 & + & - & + \\
\hline S.aureus 353 & 1.104 & + & - & - \\
\hline S. aureus 357 & 1.044 & + & - & + \\
\hline S. aureus 723 & 1.016 & + & - & - \\
\hline S.aureus 100 & 0.989 & + & - & - \\
\hline S.aureus 722 & 0.959 & + & - & + \\
\hline S.aureus 712 & 0.932 & + & - & + \\
\hline S. aureus 635 & 0.855 & - & - & - \\
\hline S.aureus 714 & 0.851 & + & - & - \\
\hline S.aureus 242 & 0.786 & + & - & - \\
\hline S.aureus 713* & 0.737 & + & + & + \\
\hline S.aureus 725 & 0.713 & + & - & - \\
\hline S.aureus 191 & 0.648 & + & - & - \\
\hline S.aureus 1559 & 0.641 & - & - & - \\
\hline S.aureus 165 & 0.585 & + & - & - \\
\hline S.aureus 636 & 0.541 & - & - & - \\
\hline S.aureus 711 & 0.528 & + & - & + \\
\hline S.aureus 1704 & 0.391 & + & - & + \\
\hline
\end{tabular}

Biofilm formation strength, was high in the two references strains followed by $S$. aureus isolate N708 $\left(\right.$ ica $^{+}$, bap and $^{-}$as $C^{+}$); similar OD values were obtained with the $S$ aureus isolate (N 635.) in which all three loci are absent. The N 713 strain, presenting all three genetic loci showed a $50 \%$ biofilm capability compared to $\mathrm{N} \mathrm{708.} \mathrm{The} \mathrm{analysis} \mathrm{of} \mathrm{antibacterial} \mathrm{activity} \mathrm{of} \mathrm{the} \mathrm{compound} \mathrm{IV} \mathrm{showed} \mathrm{that} \mathrm{it} \mathrm{was}$ effective against all planktonic forms of the tested strains with MICs values ranging from 0.4 to 0.2 $\mu \mathrm{g} / \mathrm{mL}$. The strongest biofilm producers N708, together with the reference strains S.aureus ATCC 25923, and S. epidermidis RP62A, were used to evaluate the anti-biofilm properties of pyrrolomycin IV on 24 hours established biofilms and before biofilm formation. The anti-biofilm activity against 24 hours pre-formed biofilm was observed at concentrations of 1.6 or $0.8 \mu \mathrm{g} / \mathrm{mL}$, which were higher compared to the MIC values obtained on planktonic forms (Tab.2).

Table 2: Anti-microbial activity of pyrrolomycin IV against the stronger biofilm producer strains

\begin{tabular}{cccccc}
\hline & $\begin{array}{l}\text { MIC }(\boldsymbol{\mu g} / \mathbf{m L}) \\
\text { (no growth in } \\
\text { planctonic) }\end{array}$ & \multicolumn{4}{c}{$\begin{array}{l}\text { MIC }(\boldsymbol{\mu g} / \mathbf{m L}) \\
\text { in preformed biofilm }\end{array}$} \\
\hline Strains & & $\mathbf{1 . 6}$ & $\mathbf{0 . 8}$ & $\mathbf{0 . 4}$ & $\mathbf{0 . 2}$ \\
\hline S. epidermidis RP62A & $0 \cdot 4$ & $92 \cdot 4$ & $89 \cdot .5$ & $33 \cdot 6$ & NS \\
\hline S. aureus ATCC 25923 & $0 \cdot 2$ & 54 & 41 & $30 \cdot 6$ & $\mathrm{NS}$ \\
\hline S. aureus 353 & $0 \cdot 2$ & 89 & 66 & 20 & $\mathrm{NS}$ \\
\hline S.aureus 708 & $0 \cdot 4$ & $80 \cdot 6$ & $62 \cdot 5$ & 27 & $\mathrm{NS}$ \\
\hline S.aureus $\mathbf{7 2 3}$ & $0 \cdot 2$ & 88 & 79 & 19 & $\mathrm{NS}$ \\
\hline
\end{tabular}

Values are the average of at least three independent determinations. 
Variation coefficient was less than $15 \%$. NS = not significant because below the $15 \%$ of inhibition.

The anti-planktonic activity showed MIC values between 0.2 and 0.4 for all isolates.

A higher MIC values $(0,8-1,6)$ were necessary to inhibit at least $62 \%$ in the preformed biofilm of the field isolates.

An ability of the compound to prevent biofilm on two reference staphylococcal strains and S.aureus strain N 708, was shown at concentrations of $0.18,0.09$ and $0.045 \mu \mathrm{g} / \mathrm{mL}$, lower than the MIC values established in planktonic forms. Indeed, almost $50 \%$ of biofilm was inhibited at concentration of 0.09 $\mu \mathrm{g} / \mathrm{mL}$ (Table 3 ).

Table 3: Inhibition of biofim formation at sub-MIC concentrations $(\mu \mathrm{g} / \mathrm{mL})$

The activity is expressed as percentage of inhibition.

\begin{tabular}{lccc}
\multicolumn{1}{c}{ Strains } & $\mathbf{0 . 1 8}$ & $\mathbf{0 . 0 9}$ & $\mathbf{0 . 0 4 5}$ \\
\hline S. epidermidis RP62A & 46.4 & 43.1 & 34.7 \\
\hline S. aureus ATCC 25923 & $56 \cdot 5$ & 44.5 & $29 \cdot 1$ \\
\hline S. aureus 708 & 55 & 52 & $42 \cdot 5$ \\
\hline
\end{tabular}

An average of $52 \%$ and $46 \%$ inhibitor percentage was present at sub MIC concentration of 0.18 and $0.09 \mu \mathrm{g} / \mathrm{mL}$ respectively. These results look very promising for the prevention of Biofilm formation, considering the very low level of the active concentration of compound IV.

\section{Discussion}

The results showed that the capability Staphylococcus spp. strains in biofilm formation is not related to the presence or absence of the genetic loci analysed in this study. This might be due to the fact that in vitro biofilm organization often depends on several factors such as the composition of the culture media (Ferreira et al. 2012). In contrast to human isolates, the lack of a role for the ica operon on the formation of biofilm by S.aureus isolates from bovine mastitis, has already been described (O'Gara 2007). The existence of alternative mechanisms to induce biofilm development implies that each $S$. aureus isolate might develop a particular type of biofilm matrix to better suit the environmental conditions (Schroeder et al., 2009).

Bacterial infections in livestock animals represent a big concern for food safety since the pathogenic bacteria can contaminate food products and transmit infection and disease to humans. Animal with clinical or subclinical mastitis caused by S.aureus can contaminate the milk with strains that often harbour several virulent factors like enterotoxins and toxic shock syndrome genes (Srinivasan et al. 2006). More than 280 episodes of food poisoning episodes due to staphylococcal enterotoxins have been reported each year in Europe (EFSA report, 2010). Staphylococcal enterotoxins poisoning cases and the circulation of virulent $S$. aureus strains in milk and food samples have been reported already in Sicily, Italy where mastitis problems in cattle and sheep are frequently reported (Vitale et al 2015, 2018)

\section{Conclusion}

The new synthetic pyrrolomycin IV showed good antimicrobial property against planktonic form of $S$. aureus and in preventing staphylococcal biofilm. A more efficacious control of bacterial biofilm can result in a lower number of antimicrobial treatments, a reduction in the spread of antibiotic resistance and a control of pathogenic bacteria in livestock farms. The community and sessile forms of pathogenic bacteria are in fact involved in the recurrence of infection in animals but also in persistent contamination of food production premises.

\section{Acknowledgement}

We thank Prof. Salvatore Petruso for his support in the scientific project on pyrrolomycins. Drs. Maria 
La Giglia and Nicola Sciurba for scientific support.

Funding Information

Fondi di Ateneo 2006, 2007 University of Palermo (Italy) to D.S. and R/C 2015 and 2016 by Italian Ministry of Health (Italy) to M.V.

\section{Author's Contributions}

MGC and MVR contributed to compound synthesis and biofilm assays. P.N performed genetic analysis' MV, D.S and VDLP supervised and planned the work, MV and DS contributed to manuscript writing, all authors approved the manuscript.

\section{Ethics}

The work did not involve any experiments on animals. All authors declare that no conflict of interest is present. The work is an original paper and is not under consideration in other journals.

\section{References}

Clutterbuck, A.L., Woods EJ. Knottenbelt DC. Clegg PD. Cochrane CA. Percival SL 2007. Biofilms and their relevance to veterinary medicine. Veterinary Microbiology, 121: 1-17. DOI:10.1016/j.vetmic.2007.05.029.

Cramton, SE. Gerke C. Schnell NF. Nichols WW. Gotz F. 1999. The intercellular adhesion (ica) locus is present in Staphylococcus aureus and is required for biofilm formation. Infection and. Immunity, 67: 5427-5433. PMCID: PMC96900.

Cucarella C. Tormo MA. Ubeda C. Trotonda MP. Monzon M. Peris C. Amorena B. Lasa I. Penades JR. 2004. Role of biofilm-associated protein Bap in the pathogenesis of bovine Staphylococcus aureus. Infection and. Immunity,72: 2177-2185. DOI: 10.1128/IAI.72.4.21772185.2004.

European Food Safety Authority.2010. The community summary report on trends and sources of zoonoses, zoonotic agents and food-borne outbreaks in the European Union in 2008. EFSA Journal, 8: 1496-1906. DOI: 10.2903/j.efsa.2010.1496.

Ferreira,FA. Souza RR. Bonelli RR. Américo MA. Fracalanzza SE. Figueiredo AM. 2012. Comparison of in vitro and in vivo systems to study ica-independent Staphylococcus aureus biofilms. Journal of Microbiological Methods. 88: 393-398. DOI: 10.1016/j.mimet.2012.01.007.

Melchior MB. Vaarkamp H. Fink-Gremmels J 2006. Biofilms: a role in recurrent mastitis infections? Veterinary Journal. 171: 398-407. DOI: 10.1016/j.tvj1.2005.01.006.

O'Gara JP 2007. ica and beyond: biofilm mechanisms and regulation in Staphylococcus epidermidis and Staphylococcus aureus. FEMS Microbiology Letters 270: 179-188. DOI: 10.1111/j.15746968.2007.00688.x.

Raimondi MV. Cascioferro S. Schillaci D. Petruso S 2006. Synthesis and antimicrobial activity of new-bromine-rich pyrrole derivatives related to monodeoxypyoluteorin. European Journal of Medicinal Chemistry. 41: 14394-1445. doi.org/10.1016/j.ejmech.2006.07.009.

Schillaci D. Petruso S. Raimondi MV. Cusimano MG. Cascioferro S. Scalisi M. La Giglia A.M. Vitale 2010. Pyrrolomycins as potential anti-staphylococcal biofilm agents. Biofouling. 26: 433438. doi.org/10.1080/08927011003718673.

Schroeder K. Jularic M. Horsburgh SM. Hirschhausen N. Neumann C. Bertling A. Schulte A. Foster S. Kehrel BE. Peters G. Heilmann C 2009. Molecular Characterization of a Novel Staphylococcus aureus Surface Protein (Sas C) Involved in Cell Aggregation and Biofilm Accumulation. PLoS ONE. 4(10): e7567. doi:10.1371/journal.pone.0007567. 
Simo es ML. Simo es C. Vieira MJ 2010. A review of current and emergent biofilm control strategies. LWT - Food Science and Technology. 43: 573-583. doi:10.1016/j.lwt.2009.12.008.

Srey S. Jahid IK. Ha SD 2013. Biofilm formation in food industries: A food safety concern. Food Control. 31: 572-585. doi.org/10.1016/j.foodcont.2012.12.001.

Srinivasan V. Sawant AA. Gillespie BE. Headrick SJ. Ceasaris L. Oliver SP 2006. Prevalence of enterotoxin and toxic shock syndrome toxin genes in Staphylococcus aureus isolated from milk of cows with mastitis. Foodborne Pathogens and Disease, 3: 274-283. DOI: 10.1089/fpd.2006.3.274.

Vitale, M., Scatassa ML. Cardamone C. Oliveri G. Piraino C. Alduina R. Napoli C 2015. Staphylococcal Food Poisoning Case and Molecular Analysis of Toxin Genes in Staphylococcus aureus Strains Isolated from Food in Sicily, Italy. Foodborne Pathogens and Disease. 12(1): 21-23. doi.org/10.1089/fpd.2014.1760.

Vitale M. Schillaci D 2016. Food Processing and Foodborne Illness Reference Module in Food Sciences. Editors: Elsevier doi.org/10.1016/B978-0-08-100596-5.03144-9 .

Vitale M. Gaglio S. Galluzzo P. Cascone G. Piraino C. Di Marco V. Presti Lo. Alduina R 2018. Antibiotic resistance profiling, analysis of virulence aspects and molecular genotyping of Staphylococcus aureus isolated in Sicily, Italy. Foodborne Pathogens and Disease. 15(3): 177-185. doi:10.1089/fpd.2017.2338. 